\title{
MONITORAMENTO DA CONCILIAÇÃO MEDICAMENTOSA NA ADMISSÃO DO PACIENTE
}

Lopes, A.T.A.; Cossais, C.S.; Silva T.P.; Silva, E.V.; Paiva, C.C.; Monteiro, C.H.; Gama, D.S.; Rosa, D.A.; Santos, L.T.M.

\section{INTRODUÇÃO}

Uma das barreiras utilizadas na minimização de erros relacionados a medicamento, em pontos de transição de cuidado é o processo de conciliação medicamentosa. Este consiste em uma lista única, completa, o mais precisa possível, dos medicamentos utilizados na pré-admissão de cada paciente. Essa lista é comparada com a prescrição realizada pelo médico na admissão, alta ou transferência, respeitando o momento de cada paciente e seu caso clínico. Identificadas discrepâncias, entre os itens prescritos e os medicamentos listados na admissão, o que estiver divergente deverá ser pauta de discussão junto ao prescritor, e se necessário, alterações / ajustes deverão ser realizados em prescrição. Muitos erros podem ser prevenidos através da adoção desse processo.

\section{RACIONALIDADE}

O acompanhamento das Avaliações Iniciais realizado para garantir a Conciliação Medicamentosa visa: redução das discrepâncias de registros entre membros da Equipe Multidisciplinar em prontuário / redução do potencial risco de omissão de dose de medicamento(s) de uso prévio / prevenção de eventos adversos relacionados a automedicação / prevenção de eventos adversos relacionados a autoextermínio por autoadministração de medicamento(s) que permaneça $(\mathrm{m})$ em posse do paciente / familiar.

\section{OBJETIVO}

Monitorar o total de Avaliações Iniciais (Al) da Farmácia Clínica como controle para garantir conciliação medicamentosa ao total de pacientes internados no Hospital Alvorada Moema com permanência superior a 24horas.

\section{MÉTODOS}

Análise observacional descritiva retrospectiva sobre os prontuários de pacientes internados, com Al da Farmácia Clínica ao longo de 2018, conforme dados de relatório de Reconciliação Medicamentosa extraídos do sistema WPD - SisHosp utilizado na unidade do Hospital Alvorada Moema - HAM.

\section{CONCLUSÃO}

Elaborado um formulário, fornecido ao paciente no ato da internação que deverá ser preenchido pelo próprio ou familiar / responsável legal, listando os medicamentos de uso prévio domiciliar. Observamos grande melhoria nos índices de conciliação medicamentosa na unidade HAM e consequentemente aumento da segurança deste paciente dentro do processo assistencial promovido pela Equipe de Farmácia do HAM. 